\title{
EL PAPEL DEL PARLAMENTO ESPAÑOL EN LA DEMOCRACIA DE PARTIDOS
}

\author{
POR \\ EVA SÁENZ ROYO \\ Profesora colaboradora-doctora de Derecho Constitucional \\ en la Universidad de Zaragoza
}

\section{ANTECEDENTES}

En casi todos los países de nuestro entorno el Parlamento ha sido un tema de atención preferente, habiendo sido estudiado prácticamente desde todas las perspectivas posibles. Se trata aquí de analizar el papel del Parlamento y sus miembros, o más específicamente, sus funciones en una democracia donde los partidos son los protagonistas en el sistema político, controlando el proceso electoral y convirtiéndose al mismo tiempo en sus objetos (son elegidos en cuanto partidos) y sujetos (son los partidos los que definen las campañas electorales y seleccionan candidatos y futuros parlamentarios) ${ }^{1}$. Es decir, estudiar la función del Parlamento y sus miembros en nuestra actual «democracia de partidos».

En la historia constitucional europea ya ha sido constatada la transformación que supuso en la estructura y funciones de los Parlamentos la universalización del sufragio y con ello la conversión de los partidos en protagonistas del sistema

${ }^{1}$ CоттA, «Il sotto-sistema governo-parlamento», Rivista Italiana di Sciencia Politica, 2, 1987, pág. 254. 
político ${ }^{2}$. El Parlamento decimonónico ideal, con parlamentarios independientes y generalistas, se convierte en un Parlamento de Partidos ya que son ellos los órganos de creación del Parlamento en el sentido de Jellinek ${ }^{3}$, es decir, que son los que designan en este caso los parlamentarios.

A partir de ese momento el papel jugado por el Parlamento y sus miembros dependerá en gran medida de los partidos, y en concreto, del sistema de partidos vigente en cada país. Así, en el período de entreguerras, mientras el Parlamento británico, marcado por el bipartidismo, garantizaba la estabilidad gubernamental y pasó a un segundo plano, en países con un sistema de partidos fuertemente polarizados como España, Alemania o Francia, se produjo la ruptura de la homogeneidad del Parlamento y su consiguiente fragmentación, así como un protagonismo determinante de la estabilidad gubernamental. En las democracias continentales europeas, depende del Parlamento la formación y estabilidad de los Gobiernos, cuya creciente inoperancia se atribuye, con frecuencia, a los abusos de los partidos y de los propios Parlamentos.

De ahí surgió el gran debate sobre la crisis del parlamentarismo, que algunos identifican con una supuesta crisis de la democracia representativa. Debate que contó con la participación de sociólogos, politólogos y constitucionalistas como Max Weber, Kelsen y C. Schmitt en Alemania; Duguit, Carré de Marlberg y Mirkine-Guetzévitch en Francia; Lowell y Laski en Inglaterra; Michels, Pareto y Mosca en Italia; Ortega y Gasset o Adolfo Posada en España.

De ahí también surgirían en las democracias continentales, donde se detectaba la mayor inestabilidad gubernamental, diversas medidas correctoras introducidas en las Constituciones que supusieron una reducción del papel del Parlamento. En efecto, las Constituciones de la segunda posguerra introdujeron como solución a la inestabilidad gubernamental por una parte las fórmulas que recomiendan la racionalización del parlamentarismo y que suponen toda una serie de trabas al ejercicio clásico de la exigencia de responsabilidad política; por otra parte, el establecimiento de sistemas electorales que favorecieran los sistemas de partidos no polarizados.

El resultado en la experiencia comparada ha sido la ya denunciada hace años debilidad del Parlamento. En Gran Bretaña se criticó que «es más bien el Ejecutivo quien controla a los Comunes, y no al revés» ${ }^{4}$. Por lo que respecta a Ale-

2 Sobre la evolución del papel del Parlamento en la historia política europea es muy ilustrativo SANTAMaría, Julián, "El papel del Parlamento durante la consolidación de la democracia y después», en REP, núm. 84, 1994, págs. 15-18.

3 JellineK, Allgemeine Staatslehre, 1976, págs. 545 y ss.

4 S. A. WalKLand/RYLE, The Commons in the 70s, Fontana, 1977. 
mania, Gerhard Loewenberg al evaluar el funcionamiento del Bundestag tras doce años de institucionalización criticaba aspectos que hoy se reproducen en nuestro sistema parlamentario. Así, entre otras cosas, las escasas posibilidades de los diputados para actuar como representantes de sus distritos electorales, la gran disciplina de partido que alcanza a los contenidos del debate y no sólo al sentido del voto, la falta de utilidad del Bundestag como lugar de aprendizaje para el liderazgo gubernamental y su funcionamiento bajo la dirección del Gobierno al que en realidad ni elige ni controla 5 .

En España, tras los primeros años de democracia en los que las Cortes obtuvieron un enorme protagonismo ${ }^{6}$, es a partir de 1982, con la mayoría parlamentaria socialista, cuando se empieza a vislumbrar el verdadero papel que el Parlamento jugaría en nuestro sistema político.

\section{LA DINÁMICA PARTIDISTA DE LAS CORTES ESPAÑOLAS}

El papel que cumplen las Cortes españolas viene definido por el artículo 66 de nuestra Constitución cuando señala como sus funciones la representativa, legislativa, presupuestaria y de control al Gobierno, así como las demás que le atribuya la Constitución. No obstante, quizás sea éste una de las cuestiones constitucionales, la de las funciones de las Cortes, donde existe mayor contraste entre el análisis jurídico y la realidad política. Como veremos en las páginas que siguen esas funciones no son tales o han quedado desvirtuadas en gran medida por factores como el sistema electoral, presente también en nuestra Constitución y determinante de nuestro sistema de partidos.

Nuestro Parlamento es un Parlamento de partidos. Es ésta una constatación $\tan$ asumida que casi avergüenza repetirla, y sobre la que por tanto no me voy a detener, pero que resulta esencial, de hecho es la premisa, para analizar las funciones desempeñadas por las Cortes españolas. El sistema de partidos en España,

5 LoEWEnberg, "Parliamentarism in Western Germany: The Functioning of the Bundestag», American Political Science Rewiew, 55, 1961, págs. 87-102.

6 Sobre la especial importancia del Parlamento en España en el período 1979-1982 escribieron López Garrido y Subirats, «The Spanish Cortes and the Democratic Consolidation in Spain. Relationship between Government and Parliament (1977-1987) (mimeo), citado en SANTAMARÍA, Julián, «El papel del Parlamento durante la consolidación de la democracia y después», ob. cit., pág. 15. La especial relevancia del Parlamento la atribuyen, sobre todo, a la posición minoritaria del Gobierno, la inestabilidad de la democracia, la continuidad del consenso constitucional y la debilidad ideológica del Gobierno y del liderazgo del partido que lo sostenía. 
determinado en parte por el sistema electoral, explica en gran medida la realidad de las funciones parlamentarias en la práctica.

En 1987 el politólogo italiano Cotta ${ }^{7}$ distinguía tres modelos partidistas que explicarían los diferentes papeles de las instituciones parlamentarias. Estos modelos serían:

a) El gobierno de partido en el que un partido en el gobierno es respaldado por una mayoría parlamentaria estable, unida y cohesiva, y una oposición parlamentaria relativamente fuerte. En este caso, el parlamento es el escenario en que tiene lugar la contestación pública al gobierno y a su política; sólo en un grado muy limitado sirve de estímulo para la autocorrección de las policies gubernamentales; sin embargo, es el lugar fundamental donde se forman la elite del partido y la elite gobernante, mostrando una fuerte integración entre el liderazgo del grupo parlamentario y el del partido ${ }^{8}$; en cambio, este modelo hace al gobierno directamente responsable ante el gran público, al serle confiado a individuos organizados en partidos que deben sus posiciones a la aprobación del electorado.

b) Un «modelo gran coalición» carece de la relación antagónica entre mayoría gobernante y oposición, sustituida aquí por una relación coalicional. El gobierno de coalición sobredimensionado y compacto incluye a la totalidad de partidos con representación parlamentaria, marginando sólo a aquellos partidos de escaso peso. El parlamento se convierte en un escenario del que podemos prescindir. Ni siquiera sirve como plataforma para la competencia entre gobierno y oposición, aunque continúa siendo el sitio en el que la pérdida de cohesión de la gran coalición y la crisis del modelo pueden ponerse de manifiesto.

c) El «modelo policéntrico» de organización del subsistema "gobierno-parlamento» es aplicable en las condiciones de un sistema de partidos policéntrico, donde el gobierno de coalición asiste a "connivencias» entre sectores de la propia mayoría parlamentaria (que no se sienten representados en el gobierno) y la oposición. En este modelo, escena y grupos parlamentarios pueden conquistar alguna influencia en el trabajo legislativo diario, mientras que las opciones más visibles y conflictivas dependen directamente de los líderes de los partidos.

Podríamos pensar que nuestro modelo, donde el presidente del gobierno es cabeza del ejecutivo, líder del partido mayoritario y cabeza, por tanto, del propio legislativo, donde además no ha existido nunca un gobierno de coalición, más bien responde al primero de los tipos con alguna matización que también in-

\footnotetext{
7 COTTA, «Il sotto-sistema governo-parlamento», ob. cit., págs. 259 y ss.

8 Ibid., pág. 258.
} 
fluye en el papel real de nuestro Parlamento y que analizaremos pormenorizadamente en las páginas que siguen.

En lo que aquí nos interesa existen dos preceptos constitucionales del proceso electoral que son decisivos en nuestro sistema de partidos y, por tanto, determinantes del papel de nuestras Cortes: la circunscripción provincial (art. 68.2 CE) y la fórmula proporcional (art. 68.3 CE). La fórmula proporcional d'Hondt, adoptada desde las primeras elecciones democráticas de 1977, aplicada a circunscripciones en las que el número de escaños es menor a diez, es decir, en España 44 de las 50 circunscripciones, tiene parecidos efectos a las fórmulas mayoritarias, es decir, favorece el bipartidismo estatal. Pero aplicada en las provincias en las que un partido nacionalista tiene una fuerte implantación (caso de CIU en Cataluña y PNV en el País Vasco), la fórmula electoral también actúa a su favor. Por tanto, el sistema electoral favorece el bipartidismo estatal y a los grandes partidos autonómicos. El resultado es la tendencia al bipartidismo en los partidos de ámbito estatal, con presencia de partidos nacionalistas que sirven de bisagra cuando no existen mayorías absolutas. En este sentido, el Parlamento sí podría funcionar como corrector de las políticas gubernamentales en la línea marcada por los partidos nacionalistas cuando la mayoría parlamentaria no resulte suficiente.

Analizado, aunque a grandes rasgos, nuestro sistema de partidos, veamos a continuación cómo influye en la práctica parlamentaria y, concretamente, en las funciones asignadas constitucionalmente a las Cortes Generales en nuestro artículo 66.

\section{CORTES GENERALES Y REPRESENTACIÓN}

Antes de conocer las transformaciones que la democracia de partidos ha introducido en las funciones legislativas y de control del Congreso de los Diputados, haremos una breve referencia a la mutación que la misma ha supuesto en la «función expresiva» del Parlamento", la representación. Con ello trataremos de responder hasta qué punto puede sostenerse que las Cortes, tal y como reza el art. $66 \mathrm{CE}$, «representan al pueblo español».

Este artículo al afirmar que «las Cortes representan al pueblo español» y son, por tanto, expresión de la voluntad popular, convierte al diputado en represen-

9 En palabras de Bagehot, la «representación» es la "función expresiva» del parlamento (BAGeHOT, W. The English Constitution, William Collins, Sons \& Co., Glasgow, 1983, 17 ed.). 
tante de todo el cuerpo electoral y no sólo de su circunscripción ni, menos aún, de sus concretos electores. Una vez elegido, de acuerdo con la clásica teoría de la representación parlamentaria, representa a todo el pueblo, lo que supone tanto la homogeneidad básica de aquél, como hacer de la representación lo que Smend denominaba un factor de integración funcional del cuerpo político. De hecho, la prohibición del mandato imperativo (art. 67.2 CE) garantiza esa representación impidiendo que los diputados estén sujetos a las instrucciones de los electores, grupos de presión, partidos, grupos parlamentarios, etc. En definitiva, el papel asignado por nuestra Constitución al Parlamento responde a un modelo ideal de parlamentarismo decimonónico en el que los parlamentarios, independientes y generalistas, discutían de forma libre e irrestricta acerca de todas las cuestiones de interés general y decidían con igual libertad y autonomía de criterio.

Como ya bien se sabe, esta teoría de la representación choca frontalmente con la práctica parlamentaria dirigida por los partidos políticos. Desde el momento en el que los partidos constituyen, como ya se ha dicho, el origen mismo del Congreso, adquieren éstos el protagonismo en el Parlamento a través de los grupos parlamentarios en detrimento claro del parlamentario individual. Desde la "penetración de la organización del partido en la estructura del Parlamento» los grupos parlamentarios, cualquiera que sea su naturaleza jurídica ${ }^{10}$, son en expresión de García Pelayo «componentes orgánicos del Parlamento y subunidades de la organización de los partidos» ${ }^{11}$. Esto conlleva la desaparición funcional del diputado, como así lo revela la propia historia de los grupos parlamentarios tal como ha estudiado Saiz Arnaiz ${ }^{12}$, así como que la representación se sustituya por la jerarquización siendo los diputados un mero instrumento en manos de la dirección del partido.

Este protagonismo es sin duda fortalecido, por una parte, por el sistema electoral para el Congreso de los Diputados que es un sistema proporcional y de listas cerradas y bloqueadas, según el cual los electores no seleccionan entre los candidatos individualmente considerados, sino entre los partidos que los presentan a la elección; y por otra, por el propio Reglamento del Congreso que fomenta la estructura partidista del Congreso al potenciar de diversas maneras los grupos parlamentarios en detrimento de la posición de los diputados: Desde la regulación de la formación de los grupos parlamentarios (arts. 23-25 RCD) hasta el

\footnotetext{
10 Vid. RAMíreZ, «Teoría y práctica del Grupo parlamentario», REP, núm. 11, 1975.

11 García Pelayo, M., El Estado de Partidos, Alianza, Madrid, 1986, pág. 94.

12 Saiz Arnaiz, Los Grupos parlamentarios, Congreso de los Diputados, Madrid, 1989.
} 
control de éstos ejercido sobre todos los órganos de la Cámara y por tanto sobre la actividad de la misma ${ }^{13}$.

Pues bien, el primer problema que esta realidad plantea es el de su discordancia con la teoría de la representación política, asentada en la idea del mandato libre o interdicción del mandato imperativo, que recoge el art. 67.2 CE.

En España esta contradicción se pone continuamente de manifiesto en la vida parlamentaria. Recuerda Herrero y Rodríguez de Miñón ${ }^{14}$ que en 1985, un diputado de la oposición tildó al Gobierno de representar a media España frente a la otra media. Ante tal «dislate» contra la teoría constitucional de la representación, el portavoz de su grupo parlamentario presentó excusas ${ }^{15}$. Resulta que aquél diputado no hizo sino señalar lo que realmente pensaba, como aquel niño en la famosa fábula de Andersen, frente a una mayoría que decide de común acuerdo compartir una ignorancia colectiva de un hecho obvio. Para ello no hay sino ver la percepción que aún hoy los diputados españoles tienen de su función como la de representantes del pueblo ${ }^{16}$, aún cuando su experiencia práctica no haga sino contradecirlos día a día.

En ese día a día el diputado interviene y vota según las instrucciones de su grupo, cuya eficacia garantizan una serie de medidas de disciplina y control. En este sentido, el trabajo en comisiones no añade nada al realizado en el Pleno, siendo las preferencias de los grupos parlamentarios las que deciden en ambas instancias y convirtiendo así en poco relevante y reiterativo el trabajo desarrollado en Comisión ${ }^{17}$. La dirección del grupo parlamentario decide la organización interna del grupo, distribuyendo funciones entre los distintos diputados, dando poder de acción a los diputados o convirtiéndolos en meras correas de transmisión de decisiones superiores. La dirección del grupo parlamentario de-

13 Oñate, P., "Congreso, grupos parlamentarios y partidos», en MARTínez, A. (ed.), El Congreso de los Diputados en España: Funciones y rendimiento, Tecnos, Madrid, 1999, págs. 102109.

${ }^{14}$ Herrero y Rodríguez de MiÑón, M., «El Estado de Partidos y la vida parlamentaria», en Ramírez, El Parlamento a debate, Trotta, Madrid, 1997, pág. 48.

15 DS (Congreso), 18 de noviembre de 1983. Cfr. La información periodística en $A B C, 19$ de noviembre, pág. 19.

16 Maurer, Lynn M., «Eficacia y lealtad en el Congreso de los Diputados», REP, núm. 107, 2000, pág. 85.

17 El papel irrelevante de las Comisiones contrasta con el reservado a las mismas en EEUU. $\mathrm{Al}$ respecto vid. Caballero Miguez, Gonzalo, "Comisiones, Grupos Parlamentarios y Diputados en la gobernanza del Congreso de los Diputados», Revista de Estudios Políticos, núm. 135, Madrid, 2007. Sobre la duplicación inútil de las Comisiones respecto al trabajo del Pleno vid. SANTAOLALLA, Derecho parlamentario español, Espasa Calpe, Madrid, 1990, págs. 184-185. 
termina dónde se decide (en pleno o comisiones), quiénes tienen los poderes y las funciones que de facto tiene cada órgano del Congreso. El incumplimiento de la disciplina del voto puede sancionarse de distintas formas, desde el uso de multas o sanciones económicas hasta, en caso extremo, con la expulsión del partido político.

El hecho de que el diputado se deba a su grupo hace que cada grupo parlamentario se entiende que representa, no la totalidad del electorado, sino una parte concreta del mismo, distinta de las demás. Como señala Herrero y Rodríguez de Miñón, «El "ellos" y el "nosotros" taja al Parlamento por la mitad, como tajado está el cuerpo político»" ${ }^{18}$. Así ocurre respecto a todos los grupos parlamentarios, pero resulta evidente en los nacionalistas, en cuanto pretenden expresar un hecho diferencial.

Una realidad que permitiría, por tanto, cuestionar el hecho de que hoy el Parlamento sea realmente el órgano de representación popular, tal y como debe entenderse según la teoría de la democracia representativa. Una idea que, como recuerda Rubio Llorente, ya se encuentra en la obra de Max Weber al afirmar que «La burocratización de los partidos significa que los representantes dejan de ser señores de sus electores para convertirse en servidores del jefe de su partido", pero que sería desarrollada extensamente por Leibholz ${ }^{19}$. Según este autor, el Parlamento de hoy ya no es la representación política del pueblo. La voluntad dominante no es la voluntad formada por los representantes del pueblo, sino simplemente la mayoritaria. De esta manera, nuestra democracia deja de ser representativa para ser una «democracia plebiscitaria»"

La negación de la función representativa del Parlamento en las democracias de partido supone en verdad, como han puesto de manifiesto los críticos a las teorías de Leibholz, la propia innecesariedad del Parlamento, lo cual para un demócrata resulta difícilmente aceptable. Precisamente esto ha hecho que la doctrina haya tratado de salvar la contradicción entre la teoría de la representación política y la práctica parlamentaria a través de fórmulas según las cuales el Parlamento sigue siendo representativo porque son los grupos parlamentarios, y no los diputados, los representantes libres o representantes a secas ${ }^{21}$. Estas solucio-

18 Herrero y Rodríguez de Miñón, M., «El Estado de Partidos y la vida parlamentaria», ob. cit., pág. 48 .

19 Vid. Rubio Llorente, «El Parlamento y la representación política», en La forma del poder, CEC, Madrid, 1993, pág. 229 y ss.

20 Vid. LeibHolz, Problemas fundamentales de la democracia moderna, Instituto de Estudios Políticos, Madrid, 1971.

${ }^{21}$ Rubio LlORENTE, «El Parlamento y la representación política», ob. cit., pág. 234. 
nes no resultan sin embargo satisfactorias por varias razones. En primer lugar, porque la literalidad de la prohibición del mandato imperativo del art. 67.2 CE se dirige a los parlamentarios individuales y no a los grupos parlamentarios. Pero sobre todo porque esta fórmula desconoce la vinculación que existe entre el grupo parlamentario con los órganos burocráticos del partido, algo especialmente presente en nuestro país.

Como señala Herrero y Rodríguez de Miñón, durante la primera legislatura la gran polémica de UCD fue si el Grupo parlamentario podía decidir precisamente por amplia mayoría sobre cuestiones legislativas sometidas a la Cámara. De hecho en el seno del grupo parlamentario de UCD nació un grupo de diputados, denominado los «jóvenes turcos», unidos por el común deseo de participar más activamente en las decisiones que se veían obligados a adoptar cotidianamente, cumpliendo las instrucciones de la dirección del partido y del Gobierno. La burocracia partidista reiteradamente negó la autonomía del grupo parlamentario, y en los últimos reglamentos y estatutos del PP se afirma expresa y rotundamente el absoluto sometimiento de los grupos parlamentarios a las disciplina de partido ${ }^{22}$. También se declara el absoluto sometimiento del grupo parlamentario socialista y de IU a los órganos de dirección del partido ${ }^{23}$. De hecho, la influencia de los partidos sobre los grupos parlamentarios en España es una de las más altas, sólo superada por el Reino Unido, Grecia y Portugal, siendo además que aumenta cuando el partido ostenta el Gobierno ${ }^{24}$.

Es cierto que cuando existe una identidad personal entre los miembros de los grupos parlamentarios y los líderes de los partidos no llega a apreciarse una «deslocalización» de la decisión parlamentaria. En este sentido, el Partido Conservador británico es un partido de dirección parlamentaria ${ }^{25}$, es decir, es una organización de masas con un poderoso aparato burocrático a su servicio, pero el gobierno supremo del partido no está en manos de tales burócratas ni de un liderazgo de ellos surgido, sino del grupo parlamentario de los Comunes, a su vez directamente apoyado en el electorado y muy capaz de designar y revocar el li-

${ }^{22}$ Herrero y Rodríguez de MiNón, M., «El Estado de Partidos y la vida parlamentaria», ob. cit., pág. 51. También en el art. 53 de los Estatutos del PP aprobados por el XV Congreso Nacional, celebrado en Madrid los días 1, 2 y 3 de octubre de 2004.

${ }^{23}$ Art. 75 Estatutos Federales del PSOE aprobados por el 36. ${ }^{\circ}$ Congreso Federal, celebrado en Madrid los días 2, 3 y 4 de julio de 2004; Art. 53.2 de los Estatutos Federales de IU aprobados en 2004.

24 Vid. Verge Mestre, T., Partidos y representación politica: las dimensiones del cambio en los partidos españoles, 1976-2006, CIS, Madrid, 2007, págs. 302-305 y 350.

25 Duverger, Los partidos políticos, México, 1957, págs. 211 ss.; Panevianco, Modelos de partido, Madrid, 1990, págs. 417 ss. 
derazgo político supremo. De esta manera, el elemento parlamentario desempeña una importante función.

En España, por el contrario, la tendencia es precisamente la contraria. Aunque no en igual medida en todos los partidos políticos, ya que por ejemplo en el Partido Popular por imperativo reglamentario los dirigentes del partido son también directivos del grupo parlamentario, el desarrollo de la descentralización política fomenta la aparición de los llamados «barones territoriales» de los partidos a los que les resulta poco atractivo un escaño en las Cortes Generales. De hecho, salvo el diputado que aspire a ser Presidente del Gobierno, el Congreso de los Diputados no suele servir de «ante-cámara» para acceder a la condición ministerial ${ }^{26}$, a diferencia de las demás democracias europeas ${ }^{27}$ y juega un papel cada vez más reducido en la configuración de la carrera política profesional, que se desarrolla mejor en niveles territoriales inferiores, bien política autonómica o política local. El poco deseable papel de parlamentario, que suele agotarse a sí mismo y con escaso nivel de poder real, influye en el momento de selección de candidatos en un sistema de listas cerradas y bloqueadas donde para el resultado final resultan poco relevantes los nombres seleccionados. De hecho, según los estudios del Centro de Investigaciones Sociológicas sólo un $4 \%$ del electorado vota en función de los candidatos de su circunscripción. Los líderes de los partidos quedan fuera por tanto de las Cortes mientras se incluyen en las listas personas que tienen poca relevancia en la jerarquía interna del partido. De ello resulta la ausencia de autonomía en los grupos parlamentarios y una manifiesta disyunción entre la apariencia y la realidad del sujeto de la decisión. Cada vez más la sede parlamentaria se convierte «en simple órgano de ratificación o de legitimación jurídica de las decisiones que se toman fuera de ellas» ${ }^{28}$.

En resumen, el diputado, el grupo parlamentario y, en definitiva, el Parlamento es dependiente de su origen, de los partidos políticos, y por tanto, difícilmente conciliable con el concepto de representación política. Dos realidades, la práctica y la teórica, irreconciliables, pero desde mi punto de vista imprescindibles. En una democracia de partidos, que es la democracia contemporánea, es legítimo esperar la disciplina parlamentaria, puesto que los parlamentarios elegidos no lo han sido por sus condiciones personales, sino por su inclusión en las

${ }^{26}$ Botella, J., «Parlamento y carreras políticas», en RAmíreZ, El Parlamento a debate, Trotta, Madrid, 1997, págs. 149-152.

27 Vid. Blondel/ThiéBault (eds.), The Profesión of Government Minister in Western Europe, MacMillan, London, 1991, págs. 44 y ss.

28 Solé Tura, J., y Aparicio Pérez, M. A., Las Cortes Generales en el sistema constitucional, Tecnos, Madrid, 1984, pág. 292. 
listas por un partido. No obstante, no resulta legítimo imponer esa disciplina jurídicamente. Como advierte García Pelayo, «la presencia en los textos constitucionales de la prohibición del mandato imperativo cumple, cuando menos, la función de garantizar jurídicamente la libertad de juicio y de voto del representante» ${ }^{29}$.

\section{LA FUNCIÓN LEGISLATIVA EN LA DEMOCRACIA DE PARTIDOS}

Señala el art. 66 CE como una de las funciones de las Cortes Generales la potestad legislativa del Estado. Sin embargo, en la práctica el verdadero protagonista de la actividad legislativa es el Gobierno. Esto es así no sólo en lo referente a la iniciativa legislativa, sino también a lo largo de la tramitación parlamentaria de la ley sobre la que el Gobierno ejercer un claro control.

En el Estado intervencionista contemporáneo es al Gobierno al que le corresponde la iniciativa legislativa por la complejidad que ella misma supone. Por tanto es lógico que aunque sea reconocida al Gobierno, al Congreso de los Diputados, al Senado, a las Asambleas de las CCAA y a los grupos de ciudadanos no inferiores al medio millón, según el art. $87 \mathrm{CE}$, y ésta se deba ejercer ante el Congreso, sea el gobierno el verdadero protagonista en esta fase de impulso con una prioridad constitucionalmente garantizada (art. 89.1 CE) y con la facultad reconocida de vetar iniciativas ajenas, bien por implicar disminución de ingresos o aumento de gastos (arts. 134.5 y 6 CE y arts. 111 y 126.2 RCD), bien por ser contrarios a una delegación legislativa no agotada (art. $84 \mathrm{CE}$ y arts. $126 \mathrm{RCD}$ y 128 RS). A ello se une el monopolio de la iniciativa respecto de los Presupuestos Generales del Estado (arts. 134.1 CE y 133-134 RCD).

En cuanto a la iniciativa legislativa parlamentaria, las proposiciones de ley pueden ser presentadas por un grupo parlamentario con la sola firma de su portavoz o por un diputado con la firma de otros catorce miembros de la Cámara (art. $126 \mathrm{RCD}$ ), pero recuérdese que ése es precisamente el número exigido para constituir un grupo parlamentario. De manera que en la iniciativa legislativa parlamentaria el protagonismo lo mantienen, no los diputados individuales, sino en todo caso los partidos políticos en la oposición a través de los grupos parlamentarios, pero con escasas posibilidades de salir adelante.

Como puede observarse en los cuadros, el número de proposiciones de ley presentadas por los grupos parlamentarios o por otros agentes, como las CCAA

\footnotetext{
${ }^{29}$ García Pelayo, M., El Estado de Partidos, ob. cit., pág. 100.
} 
o la iniciativa popular, no es despreciable, pero en cambio sí lo es el número de esas proposiciones que consiguen ser aprobadas. Es precisamente el grado de éxito de las iniciativas legislativas del gobierno frente a las parlamentarias lo que justifica el «tópico doctrinal» sobre la preeminencia de la iniciativa gubernamental sobre la iniciativa parlamentaria; es el porcentaje de aprobación de tales iniciativas lo que nos indica el peso específico de cada una de ellas en la realidad de la vida parlamentaria ${ }^{30}$.

PROYECTOS DE LEY

\begin{tabular}{|l|c|c|c|c|c|c|c|c|}
\hline & I legislatura & II & III & IV & V & VI & VII & VIII \\
\hline Presentados & 347 & 209 & 125 & 137 & 130 & 192 & 175 & 152 \\
\hline Aprobados & 155 & 187 & 108 & 109 & 112 & 172 & 173 & 139 \\
\hline
\end{tabular}

Fuente: Congreso de los Diputados.

\section{PROPOSICIONES DE LEY DE GRUPOS PARLAMENTARIOS Y OTRAS PROPOSICIONES DE LEY}

\begin{tabular}{|l|l|c|r|r|r|r|r|r|}
\hline & & II legislatura & $I I I$ & $I V$ & $V$ & VI & VII & VIII \\
\hline \multirow{2}{*}{ Grupos parlam. } & Presentadas & 108 & 139 & 165 & 140 & 300 & 322 & 235 \\
& Aprobadas & 14 & 9 & 18 & 17 & 28 & 16 & 18 \\
\hline \multirow{2}{*}{ Otras } & Presentadas & 20 & 33 & 35 & 38 & 50 & 47 & 82 \\
& Aprobadas & 6 & 4 & 8 & 18 & 20 & 3 & 9 \\
\hline
\end{tabular}

Fuente: Congreso de los Diputados.

Pero además del lógico protagonismo del gobierno en la fase de impulso legislativo «exitoso», la democracia de partidos ha conllevado una mediatización gubernamental a lo largo de toda la tramitación parlamentaria gracias al control que ejerce sobre el grupo parlamentario mayoritario. Precisamente la forma de control del Parlamento por el gobierno en la tramitación legislativa es a través de

30 MARTínez Sospedra recientemente parece poner en duda este «tópico doctrinal» señalando que cuantitativamente las iniciativas parlamentarias son mayores que las gubernamentales. No obstante, al analizar el porcentaje de éxito tiene que reconocer la posición privilegiada del Gobierno para sacar adelante sus iniciativas legislativas (MARTÍNEZ SOSPEDRA, «En la penumbra. Notas sobre el rendimiento del Congreso de los Diputados", Cuadernos constitucionales de la Cátedra Fadrique Furió Ceriol, núm. 50/51, 2005, págs. 162-164). 
la férrea disciplina parlamentaria. Disciplina parlamentaria que es hoy disciplina del partido a través del grupo parlamentario y fruto del interés legítimo de los propios partidos. Como advertía Leibholz, «desde el punto de vista del partido y de la fracción política, el interés de evitar (...) que el diputado pueda tomar decisiones por sí mismo con total libertad (...) es un interés muy legítimo. Hace poco un diputado comentaba: «No venimos sólo a discutir, sino que también queremos gobernar». Pero para conseguir esto es necesario que el partido se encuentre unido; hay que asegurar, pues, la homogeneidad dentro del mismo. Con la ayuda (...) de la disciplina dentro de la fracción se intenta suprimir las diferencias existentes (...) se apela a los deberes de cada diputado con su partido y se emplean a este respecto expresiones (...) tales como mandato imperativo y disciplina de fracción ${ }^{31}$.

En este sentido, las enmiendas que puedan introducirse a lo largo de la tramitación parlamentaria serán aquéllas que el propio gobierno considere necesarias para mejorar el texto u oportunas para llegar a acuerdos con otros grupos parlamentarios. Los términos de la negociación se fijan previamente por el Gobierno y el grupo parlamentario mayoritario ejecuta dicha negociación de acuerdo a los mismos. Los grupos parlamentarios y mucho más el diputado individual no escapan a ese control gubernamental en la fase de enmiendas.

Por una parte, son los grupos parlamentarios y no el parlamentario individual los que pasan a ser la clave del proceso legislativo ${ }^{32}$. El diputado ni siquiera tiene libertad para introducir enmiendas a las iniciativas legislativas ${ }^{33}$. Las enmiendas a la totalidad de los proyectos de ley sólo puede presentarlas el grupo parlamentario y las enmiendas al articulado de cualquier iniciativa legislativa

31 Leibholz, Problemas fundamentales de la democracia moderna, ob. cit., págs. 70-71.

32 Para Leibholz los Parlamentos se han convertido en «centros en los que los diputados, bajo la coacción del partido (...) llegan a sentirse en un laberinto de compromisos (...), de suerte que su efectivo papel se reduce al de unos delegados de partido, asistentes a los Pleno parlamentarios para obtener en ellos la sanción de acuerdos adoptados fuera de allí. (...) Los partidos políticos, y no, como antes, los diputados, en su calidad de personas representativas, dominan el Parlamento y pasan a ser la clave del proceso legislativo». G. LEIBHOLZ, Problemas fundamentales de la democracia moderna, ob. cit., págs. 27 y 29. En el mismo sentido añadiría más adelante: «(...) la persona del diputado, que decidía por su cuenta y obraba por iniciativa propia, creyendo representar a todo el pueblo, ha sido sustituida por el partido y la fracción política, que decide la actividad del diputado, sus discursos y votaciones» (p. 67). Tiempo atrás, Weber había calificado a los diputados de "ganado votante bien disciplinado», Weber, Economía y Sociedad, Fondo de Cultura Económica, Madrid, 1993, pág. 1087.

33 En este punto subsisten diferencias relevantes con el Senado, donde los Senadores y los Grupos se encuentran equiparados en cuanto a la facultad para presentar enmiendas legislativas (art. 107 RS). 
debe firmarlas el portavoz del grupo parlamentario, que dada la disciplina parlamentaria, aunque en teoría esa firma sea «a los meros efectos de conocimiento» es un filtro empleado por el grupo parlamentario en detrimento de la libertad del diputado (art. 110 RCD respecto a los proyectos de ley; 126 respecto a las proposiciones de ley) ${ }^{34}$. En esta misma línea, sólo los grupos parlamentarios están facultados para mantener y defender los votos particulares y enmiendas que no se incorporen al dictamen elaborado en Comisión para su discusión en Pleno (art. 117 RCD) ${ }^{35}$. Además tan sólo los grupos parlamentarios pueden retirar una proposición de ley una vez pasado el trámite de la toma en consideración (art. 129 RCD).

Por otra parte, si bien son los grupos parlamentarios de la oposición quienes protagonizan normalmente la fase de incorporación de enmiendas — dado que la iniciativa legislativa corre a cargo normalmente del gobierno-, éstas sólo saldrán adelante con el acuerdo del grupo parlamentario mayoritario, que no es sino ejecutor de las decisiones del gobierno. De ahí que la incorporación de enmiendas no persiga tanto la modificación del texto procedente del gobierno, sino la escenificación de la confrontación partidaria y, en definitiva, esta fase legislativa se torne más bien en fase de control parlamentario al gobierno.

Todo ello va sin duda en detrimento del Parlamento como "centro negociador». Los diputados tienen poca o nula capacidad de negociación con otros diputados. Las transacciones con otros grupos, las intervenciones y el voto estarán marcados por la decisión de la dirección del grupo parlamentario, que es el que determinará en cada momento las prioridades y si pertenece al grupo parlamentario mayoritario por el propio gobierno. Además sólo ciertos diputados de gran peso político, o con fuerte poder orgánico en el seno del partido correspondiente, tendrán una mayor capacidad de negociación y de establecer las prioridades del grupo político correspondiente, algo cada vez menos frecuente en nuestras Cortes.

El control último de la tramitación legislativa se ejerce por tanto por el Gobierno en detrimento del carácter deliberativo y negociador del Parlamento.

${ }^{34}$ Aboga por la supresión del requisito de la firma del portavoz en las enmiendas al articulado, ya que podría vulnerar el contenido del ius in officium derivado del derecho reconocido en el art. 23 CE, GARCÍA-ESCUDERO, "Consideraciones sobre el procedimiento legislativo ordinario en las Cortes Generales», Revista General de Derecho Constitucional, núm. 2, 2006, pág. 13; más extensamente la misma autora en El procedimiento legislativo ordinario en las Cortes Generales, Madrid, CEPC, 2006.

35 A diferencia del Senador que sí puede formular un voto particular al dictamen de la Comisión, si dicho dictamen no acepta ni incorpora su enmienda (art. 117.1 RS). 
Al fin y al cabo al margen de las negociaciones que se puedan llevar entre los grupos parlamentarios e incluso tras el mismo debate parlamentario, la decisión última determinante del resultado pertenece a una instancia que ni está en la negociación ni en la deliberación parlamentaria, al Gobierno. De esta manera, el Parlamento, «más que órgano legislativo, acaba siendo órgano sancionador de los proyectos legislativos aprobados por el Gobierno" ${ }^{36}$.

Esta omnipotencia del Gobierno en la función legislativa resulta todavía más destacable al aprobar los Presupuestos Generales del Estado. El control del Gobierno a lo largo de la tramitación legislativa es favorecido por la complejidad de la materia, de manera que con mayor rotundidad se puede afirmar que no se puede alterar por el legislador sin su consentimiento. Pero incluso enmiendas introducidas en la tramitación parlamentaria puede el Gobierno no ejecutarlas o sacarlas unilateralmente del presupuesto ${ }^{37}$.

En este sistema la sensibilidad hacia el electorado en las decisiones legislativas está en manos del gobierno, y sólo en el caso de los gobiernos en minoría y respecto a los nacionalismos en el Parlamento. De ahí que el acceso a la toma de decisiones legislativas por parte de intereses organizados sea precisamente a través de los partidos políticos o del gobierno de turno. Las «audiencias» (hearings), que tienen su origen en el derecho parlamentario anglosajón, y que suponen el contacto directo entre el parlamentario y los grupos organizados, expertos e individuos, resultan poco relevantes en nuestro Parlamento. Sólo en el caso en que esos intereses sociales no tengan un acceso directo al partido o al gobierno, el diputado puede servir como vía intermedia en esa transmisión.

Precisamente una de las formas que se ha propuesto desde la doctrina para el reforzamiento del papel del Parlamento en el proceso legislativo es a través de la potenciación de esas «audiencias» en la fase de ponencia ${ }^{38}$ o en comisión ${ }^{39}$. Si bien esta medida podría potenciar la proyección exterior del parlamentario individual, no creo sin embargo que modificara su estrecho margen de maniobra y su dependencia respecto a la decisión gubernamental al respecto. Para que tal

36 BASTIDA Freijedo, «El control del Gobierno en el derecho constitucional comparado», en RAMíreZ, El Parlamento a debate, Trotta, Madrid, 1997, págs. 94-95.

37 Sobre el papel del Parlamento en materia presupuestaria desde un punto de vista de derecho comparado puede verse GIMÉNEZ SÁNCHEZ, I., Las competencias presupuestarias del Parlamento, CEPC, Madrid, 2008.

38 LÓPEZ GUerra, «Organización y funcionamiento del Parlamento del futuro», en El Parlamento del siglo XXI, PAU I VALl (Coord.), AELPA-Tecnos, 2002, pág. 41. También Cazorla Prieto, El Congreso de los Diputados (su significación actual), Pamplona, 1999, págs. 60-62.

39 GarCÍA-Escudero, "Consideraciones sobre el procedimiento legislativo ordinario en las Cortes Generales», ob. cit., págs. 22-23. 
medida fuera realmente efectiva y no anquilosara más el proceso legislativo exigiría el reconocimiento de una autonomía al parlamentario individual que dada la estructura partidista del Parlamento y sus normas reglamentarias resulta hoy en día difícil de imaginar.

\section{CONTROL Y PARLAMENTO}

Señala el art. 66.2 CE que las Cortes Generales controlan la acción del Gobierno. Es sin duda ésta una afirmación alejada de los matices que exige una democracia de partidos. Efectivamente el control del Parlamento sobre el Gobierno tenía una clara justificación en las monarquías constitucionales en las que el poder ejecutivo carecía de la legitimidad de la que gozaban las Cortes. Es precisamente ese control, entre dos órganos de origen distinto, el que forzará el progresivo peso de las Cámaras en el nombramiento del poder ejecutivo y con ello la parlamentarización de la monarquía constitucional.

Resulta sin embargo poco justificado hablar de control de un órgano sobre otro cuando en las democracias de partidos ambos órganos quedan en parte superpuestos. Desde el momento en el que el líder del grupo parlamentario mayoritario coincide con el del poder ejecutivo, es evidente que la función de control es intraorgánica y además no será ejercida por una parte importante de los miembros de las Cortes, la mayoría parlamentaria. Esta realidad supone una transformación de la funcionalidad de los diferentes instrumentos de control parlamentario hasta el punto de aproximarse en este punto a la forma de gobierno presidencialista.

En la teoría clásica de los regímenes parlamentarios, la actividad de control se ejercía mediante los instrumentos (interpelación, pero sobre todo cuestión de confianza y moción de censura) que permitían al Parlamento exigir la responsabilidad política del Gobierno y, en último término, sustituirlo. En primer lugar, en la democracia de partidos este tipo de control ha pasado a un segundo plano, tomando protagonismo los mecanismos de control de responsabilidad difusa. Pero además, éstos tienen nuevas virtualidades hasta el punto de comerse prácticamente la acción política de los partidos ${ }^{40}$ y la actividad misma del Parlamento.

Por una parte, el parlamentarismo racionalizado convierte los instrumentos de control que conllevan responsabilidad directa del Gobierno, la moción de

40 Blanco Valdés, R., Las conexiones políticas, Alianzaensayo, Madrid, 2001, pág. 168. 
censura y la cuestión de confianza, en instrumentos de estabilidad gubernamental y protegen a los gobiernos en minorías ${ }^{41}$. De acuerdo con la Constitución, el voto de investidura y de confianza miden el apoyo al Gobierno y sólo requieren mayoría simple (arts. 112 y113 Ce) ${ }^{42}$. Por otra parte, la moción de censura requiere mayoría absoluta y obliga a sustituir al presidente por el candidato que figura en la propuesta. Si a ello sumamos la dinámica quasi-bipartidista del Parlamento español y el control gubernamental de la mayoría parlamentaria, se llega a la conclusión que este tipo de control se hace apenas practicable —al menos con la finalidad originaria de sustituir al gobierno-, sólo posible en el caso de crisis interna o fraccionamiento previo del partido mayoritario en el gobierno, lo cual resulta difícil en los regímenes políticos como el nuestro donde los partidos están ya muy consolidados ${ }^{43}$. Por esta misma razón, porque su puesta en práctica depende de la voluntad de la mayoría, resulta también difícil la constitución de otros instrumentos de control como las comisiones parlamentarias de investigación.

Por tanto, los instrumentos de control que toman protagonismo en una democracia de partidos no son aquellos que implican una responsabilidad directa del gobierno, sino los que suponen una responsabilidad difusa. Éstos además tienen nuevos objetivos y un contenido más amplio. Ya no pretenden aprobar o reprobar la actuación del gobierno pues la decisión parlamentaria es la de la mayoría ${ }^{44}$. No se trata de cambiar el contenido de la acción gubernamental, sino de debilitarla ante la opinión pública para cambiar las opciones del electorado en la

41 Aunque en Alemania la regulación es algo diferente, al menos en lo que respecta a la cuestión de confianza, el resultado es semejante. Un método que es incluso más protector de los gobiernos minoritarios es el de Escandinavia, donde no se requiere mayoría absoluta para la investidura. También en países como Francia o Italia, con un parlamentarismo racionalizado menos drástico la moción de censura y la cuestión de confianza cumplen la función de afianzamiento del gobierno. Vid. BASTIDA FREIJEDO, «El control del Gobierno en el derecho constitucional comparado", ob. cit., págs. 96-99.

${ }^{42}$ La regulación de la cuestión de confianza en Alemania (art. 68.1 LFB) requiere para su aprobación mayoría absoluta y de no obtenerla el Presidente federal, a propuesta del Canciller, puede disolver el Bundestag dentro del plazo de 21 días salvo que en dicho plazo se elija otro Canciller por mayoría absoluta.

43 Desde la aprobación de la Constitución española la cuestión de confianza sólo se ha planteado dos veces (I y IV legislatura) sin efectos apreciables y la moción de censura sólo se ha usado dos veces (I y III legislatura) a efectos simplemente demostrativos. Un balance del uso de los medios extraordinarios de control puede verse en MARTínEZ SOSPEDRA, «En la penumbra. Notas sobre el rendimiento del Congreso de los Diputados», ob. cit., pág. 167.

44 Vid. Rubio LlORENTE, "El control parlamentario», en La forma del poder, CEC, Madrid, 1993, pág. 254. 
próxima cita electoral. Como señala López Aguilar, «el Parlamento no mira ni a la tribuna ni al banco gubernamental: mira a la opinión pública ${ }^{45}$. Pero además, como señala Blanco Valdés, el contenido del control ya no se central únicamente en la acción política del Gobierno, sino en toda la acción del poder ejecutivo, así como la acción de los partidos sobre los que la mayoría se vertebra, lo que significa en nuestro Estado autonómico que el control parlamentario se ejerce también sobre las acciones de gobierno autonómicos apoyados por el mismo partido que el gobierno central ${ }^{46}$.

Es claro que en el desempeño de esta función no son todos los instrumentos de control igualmente eficaces. En este sentido, resultan especialmente importantes las preguntas, proposiciones, interpelaciones y mociones que se desarrollan en el pleno, por su mayor repercusión mediática, y si bien es precisamente en esta actividad de control donde el parlamentario individual parece tener más posibilidades de actuación autónoma según el Reglamento del Congreso, veremos que el control del grupo parlamentario, y por tanto de los partidos, se mantiene en los aspectos esenciales.

Tanto los grupos parlamentarios como los diputados (en esta ocasión, sin el visto bueno del respectivo portavoz) podrán formular interpelaciones al Gobierno (art. $180 \mathrm{RCD}^{47}$ ), no obstante en el caso de las urgentes tienen prioridad las presentadas por los grupos parlamentarios y, en todos los casos, la Mesa (no olvidemos controlada por los partidos) tiene la última palabra en su admisión (art. 181 RCD y Resolución de la Presidencia para el desarrollo de los arts. 180 a 184, en relación con el art. 67.4 del Reglamento, acerca de las interpelaciones, de 6 de septiembre de 1983). Por otra parte, su inclusión en el orden del día se lleva a cabo en atención a las circunstancias que afectan a los grupos. Además, cuando se pretenda que una interpelación dé lugar a una moción en la que la Cámara manifieste su opinión, el texto de la moción deberá ser presentado por un grupo parlamentario, no pudiendo hacerlo el diputado individual (art. 184 RCD) ${ }^{48}$, siendo difícil que salgan adelante por lo impensable que resulta que el grupo de la mayoría las apoye.

También para recabar información, datos, informes o documentos de las Administraciones públicas para el mejor cumplimiento de las funciones parla-

${ }^{45}$ López Aguilar, J. F., Minoría y oposición en el parlamentarismo. Una aproximación comparativa, Congreso de los Diputados, Madrid, 1991, pág. 225.

46 Blanco Valdés, R., Las conexiones políticas, ob. cit., págs. 174-175, 177.

47 Según el art. $170 \mathrm{RS}$, sólo los senadores y no los grupos parlamentarios pueden presentar interpelaciones.

48 Sin embargo, el RS atribuye esta facultad al Senador autor de la interpelación (art. 173.2). 
mentarias, los diputados deben contar con el previo conocimiento de sus respectivos grupos parlamentarios (art. 7.1 RCD) ${ }^{49}$. En cuanto a las proposiciones no de ley, a través de las cuales se formulan propuestas de resolución a la cámara, deben ser presentadas necesariamente por los grupos parlamentarios, al igual que las enmiendas que pudieran presentarse respecto de las mismas; también es una facultad exclusiva de los grupos parlamentarios, de la que están excluidos los diputados individualmente considerados (arts. 193 y 194 RCD).

En el ámbito donde sin duda el diputado goza de menor control partidario es en el de las preguntas. Los diputados pueden formular preguntas, tanto de carácter oral como escrito, al Gobierno, sin la autorización previa del portavoz del grupo respectivo (arts. 185 y ss RCD; en cuanto al senador art. 160 RS). No obstante, esta función carece de la agilidad introducida en otros sistemas parlamentarios, como las question time $e^{50}$, además de que queda mermada por cuanto el grupo mayoritario, que no desempeña la función de control, se reserva parte de las preguntas orales a los ministros, en la mayoría de las ocasiones dictadas por el propio gobierno para lucimiento de sus políticas. Por otra parte, el objetivo de las preguntas de la oposición no es tanto el de conseguir información, como en provocar erosión en la mayoría parlamentaria. Además respecto a las preguntas con respuesta oral en el Pleno, que son las de mayor repercusión pública, existen una serie de previsiones que les dan el total protagonismo a los grupos parlamentarios en detrimento al parlamentario individual. En primer lugar, su formulación y tramitación está condicionada por la asignación de un cupo máximo a cada Grupo Parlamentario (art. 188.2 RCD y 163.2 RS). Pero sobre todo, son las normas supletorias dictadas en ambas Cámaras - Resolución de la Presidencia del Congreso de los Diputados de 18 de junio de 1996 y la Norma supletoria de la Presidencia del Senado de 23 de mayo de 2001 - las que otorgan amplios poderes a los grupos parlamentarios para decidir sobre las preguntas formuladas por sus miembros. En concreto, las normas habilitan a los Grupos a sustituir cualquiera de las preguntas que hayan formulado sus integrantes por otras relativas a los acuerdos adoptados por el Consejo de Ministros; correspondiendo también al Grupo indicar qué Diputado o Senador integrante del mismo efectuará la nueva pregunta (puntos 7 y 11 de las Resoluciones respectivas). También habilitan a los Grupos a sustituir las preguntas que hayan for-

49 Este derecho corresponde también a un tercio de los Senadores miembros de una Comisión (art. 67 RS).

50 Son preguntas con respuesta oral, que permiten preguntas adicionales, lo que exige la improvisación del ministro. Así en Francia encontramos las questions au Gouvernement y las questionscrible; en Italia las preguntas con respuesta inmediata. 
mulado sus miembros por otras de especial actualidad o urgencia, que serán planteadas por el parlamentario que indique el Grupo (puntos 9 y 13 respectivamente). También son los grupos los que deciden sobre la preferencia en la tramitación de las preguntas formuladas por sus integrantes (puntos 6 y 7 respectivamente). En definitiva, son las direcciones de los grupos parlamentarios quienes deciden qué se pregunta y quiénes plantearán las preguntas orales en Pleno, convirtiéndose su reparto en un sistema de premio-castigo con respecto a los miembros que componen el grupo.

La democracia de partidos ha supuesto por tanto una decadencia de los derechos de control por parte de los diputados individuales ${ }^{51}$, pero también una mutación de los objetivos perseguidos por ese control. Ahora los instrumentos de control son utilizados por los grupos parlamentarios en la oposición para explicitar la lucha partidaria, convirtiendo así al Parlamento en el escenario oficial de dicha lucha o escenario de la crítica de los partidos de la oposición a la acción del gobierno o, en términos de Steffani ${ }^{52}$, en un legislativo retórico (talk legislature) que aspira a ser «la plataforma oficial de todos los grandes debates que sacuden a la nación».

No obstante, para el ejercicio de dicha función "publicitaria» es también el Parlamento dependiente de otro factor externo, los medios de comunicación cuyo importancia en las actuales democracias de partidos es indiscutible hasta el punto de poder hablar, con Sartori, de «teledemocracia». Los medios de comunicación, al jerarquizar los temas o asuntos relevantes para los ciudadanos, intervienen decisivamente en la fijación de la agenda del Parlamento, alterando en buena medida la actividad parlamentaria ${ }^{53}$. No puedo detenerme en este aspecto, pero sí me gustaría subrayar lo que a este respecto ha señalado Blanco Valdés: que son precisamente los mass media, no controlados por los partidos, los que convierten el control parlamentario en bidireccional, de manera que según el uso que haga la oposición de los instrumentos parlamentarios de desgaste político del gobierno se convierta ella misma en víctima la acción controladora ${ }^{54}$.

51 Como dice Leibholz, «el cambio estructural de la democracia parlamentaria y representativa a un Estado de Partidos ha producido una sensible disminución de los derechos de control, primero de los diputados en particular, después también de las fracciones políticas y, finalmente, de todo el Parlamento». Leibholz, Problemas fundamentales de la democracia moderna, ob. cit., pág. 72.

52 STEFFAnI, W., «Amerikanischer Kongress und Deutscher Bundestag -ein Vergleich», Aus Politik und Zeitgeschichte, B43/65, págs. 12-24.

53 Vid. PAU I VAll (Coord.), Parlamento y comunicación (nuevos retos), AELPA-Tecnos, 2005; también trata del tema Guerrero Salom, E., El Parlamento: qué es, cómo funciona, qué hace, Ed. Síntesis, Madrid, 2004, págs. 243 y ss.

54 BlanCO VAldÉs, R., Las conexiones politicas, ob. cit., págs. 187-188. 


\section{CONCLUSIÓN ¿CUÁL ES EL PAPEL REAL DEL PARLAMENTO EN LA DEMOCRACIA ESPAÑOLA DE HOY?}

Hasta aquí no podríamos afirmar que el papel de nuestro Parlamento se aleja mucho del papel asignado en democracias parlamentarias más consolidadas y que responden al tipo "gobierno de partido» definido por Cotta. En efecto, el Parlamento español, en el ejercicio de su función de control, es el escenario en que tiene lugar la contestación pública al gobierno y al partido que lo sostiene; sólo desde esta perspectiva, se podría sostener que el Parlamento es un órgano que representa a todo el pueblo por cuanto en él quedan reflejadas las plurales ideologías de una determinada sociedad; y en el ejercicio de la función legislativa en la mayoría de los casos es simple sancionador de los proyectos legislativos del gobierno, de manera que su voluntad no es la general, sino la expresión de la voluntad de la mayoría. En estos casos también la función de control prima sobre la legislativa, ya que la presentación de iniciativas o enmiendas no pretende tanto modificar esa decisión mayoritaria como escenificar la confrontación partidista. Sólo en limitadas ocasiones, cuando no existen mayorías absolutas y el partido mayoritario depende para sacar adelante sus proyectos de los partidos bisagras nacionalistas, el Parlamento puede servir para corregir las políticas gubernamentales potenciándose la sede parlamentaria como "centro de negociación». En todo caso, es un modelo que hace al gobierno directamente responsable ante el gran público, mientras el Parlamento se convierte en la sede de la confrontación partidista con vistas a la próxima cita electoral, que adquiere cierto matiz plebiscitario ${ }^{55}$.

Quizás la diferencia con otras democracias parlamentarias y que fomenta en mayor medida la debilidad de nuestras Cortes es que no es el lugar fundamental donde se forman la elite del partido y la elite gobernante, mostrando una manifiesta disyunción entre la apariencia y la realidad del sujeto de la decisión. En este sentido, hemos visto cómo frente al Partido Conservador británico, que es un partido de dirección parlamentaria, en España, por el contrario, la tendencia es precisamente la contraria, es decir, la inclusión en las listas de personas que tienen poca relevancia en la jerarquía interna del partido, haciendo más patente la dependencia del Parlamento respecto de los partidos.

Resulta, por tanto, claro que el papel del Parlamento en España se corresponde más bien poco con el modelo ideal establecido constitucionalmente. El

55 De hecho, como señala García Pelayo, «aunque formalmente elegido por las vías de la democracia representativa y con los debidos ritos parlamentarios, el proceso por el cual (se) asciende a Jefe de Gobierno tiene, en su punto de partida, un cierto matiz plebiscitario» (GARCÍA PELAYO, M., El Estado de Partidos, ob. cit., pág. 108). 
protagonismo adquirido de los partidos políticos en los sistemas parlamentarios reduce inevitablemente la relevancia parlamentaria en los sentidos apuntados, agudizándose esa debilidad en nuestro sistema por varios elementos. En primer lugar, por un sistema electoral proporcional y con listas cerradas y bloqueadas para el Congreso que sin duda agudiza la dependencia de los candidatos respecto de los partidos. En segundo lugar, por unos Reglamentos que suponen un fortalecimiento de los grupos parlamentarios en detrimento de los parlamentarios. $\mathrm{Y}$ en tercer lugar, por la «exclusión parlamentaria» de los sujetos de decisión, los líderes de los partidos.

Esta constatada debilidad de nuestras Cortes no creo que pueda calificarse como de crisis del Parlamento, sino más bien adaptación del mismo a las nuevas necesidades de una sociedad de partidos. No obstante, creo también que sería necesaria la adaptación del Reglamento de las Cámaras a las verdaderas funciones desempeñadas por el Parlamento, a la vez que establecer unos límites que permitan reconocer la institución parlamentaria y sus miembros como tales, de manera que su adaptación no suponga su total desaparición. Al fin y al cabo el Parlamento tiene que seguir siendo el centro del sistema democrático y de su prestigio se derivará el prestigio del sistema mismo.

Respecto a lo primero, es decir, la adaptación del Reglamento de las Cámaras a las verdaderas funciones desempeñadas por el Parlamento, las modificaciones tendrían que tener una doble perspectiva, dado que necesariamente la regulación reglamentaria debe estar apegada a la realidad política por razones de eficiencia. En el ámbito legislativo, donde es la decisión mayoritaria la determinante, y siendo que esta decisión mayoritaria no es la de la suma de los miembros del Parlamento sino la de los partidos, debería primarse el procedimiento del voto ponderado y por tanto el trabajo de las comisiones. Esto supondría sin duda una forma de agilización de la tramitación legislativa, hoy extremadamente reiterativa y anquilosada, aún a costa de poner más en cuestión la «función representativa» del Parlamento, ya que al fin y al cabo el «pleno» es el único lugar en el que los representantes del pueblo ostentan plenamente esta condición. Por otra parte, en el ámbito del control y dado que la funcionalidad del mismo ya no es la reprobación del gobierno, sino su crítica por parte de los grupos parlamentarios de la oposición, son fundamentalmente éstos los que tendrían que tener en sus manos los instrumentos de control al gobierno ${ }^{56}$, que ten-

56 Sobre la práctica parlamentaria durante la VIII Legislatura de limitar las preguntas orales de la mayoría parlamentaria a la cuarta parte en cada sesión plenaria se pronuncia ARANDA ÁLVAREZ, E., "Transformaciones en los instrumentos de control parlamentario», Teoría y Realidad Constitucional, núm. 19, 2007, pág. 112. 
drían que ser más ágiles y desarrollarse esencialmente en el Pleno como "plataforma oficial de la lucha partidista». Sin duda estas modificaciones supondrían un acercamiento del funcionamiento interno del Parlamento al papel por él mismo desempeñado.

Por otra parte, no creo que modificaciones en nuestro sistema electoral supusieran un cambio sustancial en el papel hoy desempeñado por nuestras Cortes. Los sistemas electorales, como manifiesta Giovanni Sartori, pueden determinar la forma en que los votos, al transformarse en escaños, afectan la conducta del votante en relación a si éstos votan por un partido o por una persona ${ }^{57}$. Un sistema electoral como el nuestro, proporcional y con listas cerradas y bloqueadas para el Congreso, es cierto que agudiza la desaparición del diputado individual y da mayor relevancia al partido. Por una parte, incentivan la jerarquía política, pues los diputados que buscan la posibilidad de reelección están incentivados a seguir las directrices de la dirección de su partido político, pues será ésta la encargada de decidir quién formará parte de las listas electorales del partido en las elecciones siguientes. A su vez los electores votan más en función de los partidos, programas y equipos que en función de los parlamentarios singulares que se presentan en cada circunscripción concreta salvo en lo que se refiere al líder o a una minoría de líderes de este o aquel partido ${ }^{58}$. Los electores sólo pueden optar entre los distintos partidos políticos que se presentan, y no entre los candidatos de los distintos partidos. El protagonismo político reside en los partidos, y la acción individual de un parlamentario al margen de su partido es irrelevante. Esto establece un sistema de incentivos para el elector. De hecho, según los estudios del Centro de Investigaciones Sociológicas sólo un 4\% del electorado vota en función de los candidatos de su circunscripción, además de que este sistema tiene una escasa valoración en cuanto fórmula que permita seleccionar a los mejores gobernantes (dos de cada tres españoles están bastante o muy en desacuerdo con que valga para eso $\left.{ }^{59}\right)$. En definitiva, nuestro sistema electoral favorece el protagonismo de las direcciones y líderes de los partidos políticos frente a los candidatos individuales.

Es cierto que una modificación de nuestro sistema electoral influiría necesariamente en el proceso de selección de candidatos, al que los politólogos bri-

57 SARTORI, Giovanni, Ingeniería constitucional comparada. Una investigación de estructuras, incentivos y resultados, FCE, México, 1996, págs. 27-38.

58 García Pelayo, M., El Estado de Partidos, ob. cit., pág. 83.

59 A. de MIGUEL, La sociedad española, 1992-1993, Alianza, Madrid, 1992, pág. 719; JEREZ, M., «La élite parlamentaria», en RAMíreZ, El Parlamento a debate, Trotta, Madrid, 1997, pág. 136. 
tánicos aluden como el «jardín secreto de la política» ${ }^{60}$. Podría motivar a los partidos a incluir en sus listas a personas valoradas socialmente, con claridad de juicio, criterio y sensibilidad hacia las preocupaciones del electorado. Todo contribuiría a un mayor prestigio de la condición de diputado y, por ende, de la institución parlamentaria. Pero no creo que esto supusiera un cambio sustancial del papel que esos parlamentarios desempeñaran en el Parlamento. De hecho en Inglaterra también podríamos decir que hay, en terminología de Mezey, un Parlamento reactivo, en el que "los diputados se amoldan a los ideales del partido en vez de a las peticiones directas del electorado ${ }^{61}$, aunque se siga utilizando el sistema del sufragio mayoritario en distritos uninominales a una sola vuelta y rija por tanto la dinámica del winner takes it all. La diferencia principal con respecto a nuestro Parlamento es el peso específico de los parlamentarios británicos en el partido. En la medida de lo posible, habría que tratar de disminuir la disyunción entre la apariencia y la realidad del sujeto de decisión parlamentaria en España. Todo ello va en detrimento de la valoración popular a los parlamentarios y, por extensión, al Parlamento mismo. Pero también creo que esa disyunción es consustancial a nuestro desarrollo autonómico y a la proliferación de elites políticas territoriales.

El débil papel del Parlamento en la democracia española creo que es algo consustancial a nuestro sistema de partidos y también necesario, como históricamente se ha demostrado, para salvar la estabilidad gubernamental. Para Colliard, para lograrla es necesario «una articulación estrecha entre la mayoría parlamentaria y el ejecutivo», y por tanto la clave es «la definición del parlamento como elemento de referencia y comité legislativo del gobierno» ${ }^{62}$. Pero tampoco hay que olvidar que sigue funcionando como órgano que representa a todo el pueblo por cuanto en él quedan reflejadas las plurales ideologías de una determinada sociedad. Es en esta faceta donde reside hoy su esencia y en definitiva su necesidad en nuestro sistema político.

${ }^{60}$ M. Gallagher y M. Marsh (eds.), Candidate Selection in Comparative perspective: the Secret Garden of Politics, Sage, London, 1988.

${ }_{61}$ MezeY, Michael, Comparative Legislatures, Durham NC, Duke University Press, 1979, pág. 40.

${ }^{62}$ COLliard, Los regimenes parlamentarios contemporáneos, Editorial Blume, Barcelona, 1981, pág. 338. 


\section{BIBLIOGRAFÍA}

ARANDA ÁlVAREZ, E., "Transformaciones en los instrumentos de control parlamentario», Teoría y Realidad Constitucional, núm. 19, 2007.

Bagehot, W., The English Constitution, William Collins, Sons \& Co., Glasgow, 1983, 17 ed.

BASTIDA FREIJEDO, «El control del Gobierno en el derecho constitucional comparado», en RamíreZ, El Parlamento a debate, Trotta, Madrid, 1997.

Blanco Valdés, R., Las conexiones politicas, Alianzaensayo, Madrid, 2001.

Blondel/Thiébault (eds.), The Profesión of Government Minister in Western Europe, MacMillan, London, 1991.

Botella, J., «Parlamento y carreras políticas», en RAMíReZ, El Parlamento a debate, Trotta, Madrid, 1997.

CaAmaño DomíngueZ, El mandato parlamentario, Congreso de los Diputados, Madrid, 1991.

Caballero Miguez, Gonzalo, "Comisiones, Grupos Parlamentarios y Diputados en la gobernanza del Congreso de los Diputados», Revista de Estudios Políticos, núm. 135, Madrid, 2007.

Cazorla Prieto, El Congreso de los Diputados (su significación actual), Pamplona, 1999.

COTTA, «Il sotto-sistema governo-parlamento», Rivista Italiana di Sciencia Politica, 2, 1987.

DUVERGER, Los partidos políticos, México, 1957.

Gallagher/Marsh (eds.), Candidate Selection in Comparative perspective: the Secret Garden of Politics, Sage, London, 1988.

GARCÍA-ESCUDERO, «Consideraciones sobre el procedimiento legislativo ordinario en las Cortes Generales», Revista General de Derecho Constitucional, núm. 2, 2006.

- El procedimiento legislativo ordinario en las Cortes Generales, Madrid, CEPC, 2006.

García Pelayo, M., El Estado de Partidos, Alianza, Madrid, 1986.

Giménez SÁnCHEZ, I., Las competencias presupuestarias del Parlamento, CEPC, Madrid, 2008.

Guerrero Salom, E., El Parlamento: qué es, cómo funciona, qué hace, Ed. Síntesis, Madrid, 2004.

Herrero y RodrígueZ de Miñón, M., «El Estado de Partidos y la vida parlamentaria», en RAMíreZ, El Parlamento a debate, Trotta, Madrid, 1997.

JELLINEK, Allgemeine Staatslehre, 1976.

JEREZ, M., "La élite parlamentaria», en RAMíREZ, El Parlamento a debate, Trotta, Madrid, 1997.

LeibHolZ, Problemas fundamentales de la democracia moderna, Instituto de Estudios Políticos, Madrid, 1971.

LIEBERT, Ulrike, "Parlamento y consolidación de la democracia en la Europa del Sur», REIS, 42/88. 
LOEWENBERG, "Parliamentarism in Western Germany: The Functioning of the Bundestag», American Political Science Rewiew, 55, 1961.

López Aguilar, J. F., Minoría y oposición en el parlamentarismo. Una aproximación comparativa, Congreso de los Diputados, Madrid, 1991.

LÓPEZ GUERRA, «Organización y funcionamiento del Parlamento del futuro», en El Parlamento del siglo XXI, PAU I VAll (Coord.), AELPA-Tecnos, 2002.

MARTÍnEZ SOSPEDRA, «En la penumbra. Notas sobre el rendimiento del Congreso de los Diputados», Cuadernos constitucionales de la Cátedra Fadrique Furió Ceriol, núm. 50/51, 2005.

Maurer, Lynn M., «Eficacia y lealtad en el Congreso de los Diputados», REP, núm. 107, 2000.

Miguel, A. De, La sociedad española, 1992-1993, Alianza, Madrid, 1992.

OÑATE, P., "Congreso, grupos parlamentarios y partidos», en MARTínEZ, A. (ed.), El Congreso de los Diputados en España: Funciones y rendimiento, Tecnos, Madrid, 1999.

Ortega Santiago, Carlos, El mandato representativo de los diputados y senadores, Congreso de los Diputados, Madrid, 2005.

PaneVianco, Modelos de partido, Madrid, 1990.

PAU I VAll (Coord.), Parlamento y comunicación (nuevos retos), AELPA-Tecnos, 2005.

RAMíREZ, «Teoría y práctica del Grupo parlamentario», REP, núm. 11, 1975.

— «Problemática actual del Parlamento», REP, núm. 87, 1995.

Rubio LlORENTE, «El Parlamento y la representación política», en La forma del poder, CEC, Madrid, 1993.

— «El control parlamentario», en La forma del poder, CEC, Madrid, 1993.

SANTAMARÍA, Julián, "El papel del Parlamento durante la consolidación de la democracia y después», en REP, núm. 84, 1994.

SaIZ Arnaiz, Los Grupos parlamentarios, Congreso de los Diputados, Madrid, 1989.

SantaOlalla, Derecho parlamentario español, Espasa Calpe, Madrid, 1990.

SARTORI, Giovanni, Ingeniería constitucional comparada. Una investigación de estructuras, incentivos y resultados, FCE, México, 1996.

Solé Tura, J., y APARICIO PÉREZ, M. A., Las Cortes Generales en el sistema constitucional, Tecnos, Madrid, 1984.

STEFFAnI, W., "Amerikanischer Kongress und Deutscher Bundestag -ein Vergleich», Aus Politik und Zeitgeschichte, B43/65.

TOMÁs MALlÉN, B., Transfuguismo parlamentario y democracia de partidos, CEPC, Madrid, 2002.

VALENCIA ESCAMILla, L., "Modernidad institucional y cambios en la función parlamentaria", en Revista Mexicana de Derecho Constitucional, núm. 7.

Verge Mestre, T., Partidos y representación política: las dimensiones del cambio en los partidos españoles, 1976-2006, CIS, Madrid, 2007.

WaLKLAND/RYLE, The Commons in the 70s, Fontana, 1977.

WEBER, Economía y Sociedad, Fondo de Cultura Económica, Madrid, 1993. 
Title

THE FUNCTIONS OF THE SPANISH PARLIAMENT IN THE DEMOCRACY OF PARTIES

\title{
Summary
}

1. Antecedents; 2. The partisan dynamics of the Spanish Parliament; 3. Parliament and Representation; 4. The legislative function in the democracy of parties; 5. Control and Parliament. 6. Conclusion: Which are the real functions of the Parliament in the Spanish democracy. Bibliography

\section{Resumen}

El papel que cumplen las Cortes españolas viene definido por el artículo 66 de nuestra Constitución cuando señala como sus principales funciones la representativa, legislativa, presupuestaria y de control al Gobierno. No obstante, quizás sea éste una de las cuestiones constitucionales, la de las funciones de las Cortes, donde existe mayor contraste entre el análisis jurídico y la realidad política. En estas páginas se trata de analizar las mutaciones que nuestro sistema de partidos ha provocado en las funciones asignadas constitucionalmente a las Cortes Españolas y conocer el papel real que hoy desempeña en España el Parlamento y sus miembros.

Tras enmarcar la cuestión del papel del Parlamento en la historia constitucional europea, se analizan los elementos electorales de la Constitución española de 1978 que explican la dinámica partidista de las Cortes, para a continuación tratar de responder en qué medida puede afirmarse que las mismas «representan al pueblo español», ejercen la potestad legislativa y presupuestaria o controlan al Gobierno. Veremos cómo el protagonismo adquirido de los partidos políticos en nuestro sistema parlamentario ha desvirtuado en gran medida dichas funciones y les ha dotado de nuevas funcionalidades. Finalmente proponemos posibles reformas que hagan más acorde el funcionamiento interno del Parlamento con el papel real que el mismo juega.

\begin{abstract}
The main functions of the Spanish Parliament - the representative one, legislative, budgetary and control the Government - are defined by article 66 of our Constitution. Perhaps however, it is one of the constitutional questions, the functions of Parliament, where greater resistance between the legal analysis and the political reality exists. These pages analyze the mutations that our system of parties has caused in
\end{abstract}


the functions assigned constitutionally to Spanish Parliament and, consequently, the paper real that today carries out in Spain the Parliament and its members.

After framing the question of the functions of the Parliament in European constitutional history, the electoral elements of the Spanish Constitution of 1978 are analyzed. These elements explain the partisan dynamics of Cortes. Later the article analyzes to what extent it can affirm that the same «represent the Spanish people», exert the legislative and budgetary power or control the Government. We will see how the acquired protagonism of the political parties in our parliamentary system has weakened these functions and it has equipped to them with new functionalities. Finally we propose possible reforms that make the internal working of the Parliament agreed with its real functions.

\section{Palabras clave}

Parlamento, Partidos, Funciones parlamentarias

Key words

Parliament, Parties, Parliamentary functions 